Article

\title{
Far Red and Red as Factors Forming Physiological Processes in Spring Barley under Controlled Conditions
}

\author{
Andrzej Doroszewski (D), Teresa Doroszewska (D) and Anna Podleśna * (D) \\ Institute of Soil Science and Plant Cultivation-State Research Institute, Czartoryskich 8 str., \\ 24-100 Puławy, Poland; ador@iung.pulawy.pl (A.D.); dorter@iung.pulawy.pl (T.D.) \\ * Correspondence: ap@iung.pulawy.pl
}

Received: 16 November 2020; Accepted: 17 December 2020; Published: 20 December 2020

check for updates

\begin{abstract}
Solar radiation is a very important energy source for life on Earth and especially for the proper growth and development of plants. Its spectral composition is necessary for a main physiological process in a plant's life-photosynthesis. In practical agriculture, plants are cultivated in the stand, which causes neighboring plants not only to compete for water and nutrients but also for light. Living in such an environment, plants have developed different mechanisms for dealing with shading. An aim of the studies conducted here was to determine the effect of the red (R) and far red (FR) range of spectral composition on gas exchange and the other physiological features of spring barley plants. The experiment was conducted in two growth chambers with different spectral compositions of radiation. Spring barley was grown in Mitscherlich pots. The physiological features measured during the two barley developmental phases, i.e., seventh and flag leaves, differed depending on the R/FR ratio used in these chambers. Plants that grew under conditions of a high R/FR ratio showed a higher photosynthesis efficiency, intracellular $\mathrm{CO}_{2}$ concentration, stomatal conductance and transpiration of water but lower values of the water use efficiency (WUE) index. The leaves of plants treated with this kind of light (higher R/FR ratio) had a greater stomata number and higher content of chlorophyll when compared to plants grown under conditions with a low R/FR ratio.
\end{abstract}

Keywords: spectral composition; radiation; photosynthesis; chloroplasts; water use efficiency

\section{Introduction}

The spectral composition of solar radiation plays one of the main informative and signaling roles in plant development. The possibility of monitoring the number, quality and direction of radiation changes allows plants to optimize light energy absorption, which is necessary for photosynthesis. Using transmitted and reflected radiation, they detect the presence of neighboring plants and then create appropriate competitive responses, allowing them to get an advantage over the other plants. The capability of plants to detect the presence of neighboring plants has caused the development of some mechanisms that allow them to survival in adverse environmental conditions. One of the important stress factors for plants is shading; however, they have two ways of doing this: avoid it or tolerate it.

The avoidance of shading is one of the more necessary competitive strategies. The ability to detect and respond to upcoming shading is an important feature of plants growing in natural environments. Competition between single individuals is a result of the response to light shortage and the spectral composition of radiation. One of the main signals of shading is a decrease of the red ( $R$ ) to far red (FR) ratio in transmitted radiation reflected from neighboring plants [1-3]. Shade avoidance syndrome (SAS) $[2,4,5]$ is frequently caused by FR reflected from neighboring plants, even before the growth of 
the stand, which means that plants can detect and react to potential future competition just before the shading [1,6-8]. Natural shading in stands give a low R/FR ratio $[9,10]$ when compared to natural solar radiation in an open space [11,12] because a high absorption of chlorophyll and other photosynthetic pigments in the range of the blue and red spectrum causes the absorption of radiation in this range to be high, while in the range above $700 \mathrm{~nm}$ it is relatively low.

The detection of neighboring plants is possible by radiation from the range of the blue spectrum $[5,13,14]$, which, to a great degree, is reduced in its absorption effect by competitive plants. An important signal for avoiding shading is also a low value of radiation, especially in the range of Photosynthetically Active Radiation (PAR) $[1,5,15]$. An important element in the protection strategy against unfavorable conditions is the ability to receive light signals by photoreceptors. Phytochromes belong to the more important among them.

In the angiosperms, in the most numerous group of plants in the world, three main phytochromes generally occur: phyA, phyB and phyC [15].

The phyA is a photoreceptor registering FR presence in the environment and then mediating photo-morphogenetic reactions as a response to a signal from this spectrum range [16]. PhyB strongly reacts to changes of the R/FR ratio [16,17], and even its small changes cause great photo-morphogenetic effects [18]. Under conditions of radiation, a reduction of phyB occurs with a low R/FR ratio, a form of phytochrome that absorbs far red $\left(\mathrm{P}_{\mathrm{fr}}\right)$, and at the same time the initiation of a reaction referred to as shading avoidance syndrome (SAS) follows. PhyB plays a dominant role in mediating other neighbors' plants detection [5] and shading avoidance reactions [15].

Phytochromes A and B perform a very important function, which consists in the mediation of radiation (in the range of red) in the promotion of stomata production [19]. The role of the phytochrome $\mathrm{D}$ (phyD) is to evaluate changes in the R/FR ratio. It was found that phyE mediated the reaction of shading avoidance and responses to the R/FR ratio [20-25].

With the exception of performing the role of radiation detection, a phytochrome is a key player, playing decidedly the most important role in the shading avoidance process. In 1982, Smith [4] put forward a hypothesis about the perception of the R/FR ratio as a fundamental function of a phytochrome. A plant evaluates the presence of a neighbor by monitoring a signal reflected from green tissues, characterized by a greater share of far red in relation to red. Changes in the amount of far red are correlated with the plant's density and proximity to neighboring plants $[6,7,26,27]$. The R/FR ratio in the stand decreases together with the density of green plants $[26,28,29]$. Through the perception of the $\mathrm{R} / \mathrm{FR}$ ratio via the phytochrome, plants determine the degree of shading. In response to this signal, plants trigger shading avoidance reactions. A relatively small increase of the FR amount causes an enlarged elongation growth and even a negative phototropic response (as a bending over from neighbors' plants) [5]. PhyB is mostly responsible for the plant's ",shade avoidance response" to a low R/FR ratio [4], and to a lesser degree phyD and phyE take part in this reaction $[15,16,25]$. It is particularly emphasized that even small changes in the R/FR ratio cause considerable changes in photo-morphogenesis [27].

It should also be noted that under the conditions of a radiation with a low R/FR ratio, the activity of auxins (IAA19) increases considerably, which also takes part in the process of shading avoidance by interacting with DELLA protein [28].

Radiation in the blue range also plays a significant role in the photo-morphogenesis. A little amount of this radiation determines some photo-morphogenetic reactions [25,29].

Radiation from the range of $\mathrm{R}$ is absorbed by the chlorophyll, whereas radiation from the range FR is reflected and transmitted by the leaves, causing a considerable increase in the FR amount in the surrounding of the plants [30]. The first signal indicated by the presence of neighboring plants is generated at the moment when the FR participation increases. Together with plant growth, leaves' density decreases and the reflected radiation in the range of the FR increases, so consequently a lowering of the R/FR ratio occurs.

The enrichment of radiation with the additional FR during a few minutes before the dark period caused the number of stomata on the lower and upper side of the tobacco leaves to be lower than 
for plants that were lit by an additional amount of $\mathrm{R}$ [31]. The biggest degree of stomata opening was observed after radiation by the blue and red parts of the spectrum, and using a system in which plants were first treated with the radiation ranges $R$ and $B$ and then FR caused a lower degree of their opening [32].

A few minutes of exposure of FR before the dark period causes chloroplasts in the tobacco leaves to contain a lower granum than after a similar treatment with red or full white light $[33,34]$.

The aim of this research, led under precisely controlled conditions, was the determination of the spring barley response to different spectral compositions, especially in the range of $R$ and FR.

\section{Materials and Methods}

The experiments were conducted under control conditions in two climatic chambers, HERAEUS firm, with the use of artificial sources of radiation. In each of these chambers different spectral compositions of radiation were used through the use of bulbs and fluorescent lamps from the Philips company and halogen lamps of the PAR30 rosé type form the Paulmann company (Table 1).

Table 1. Sources of the radiation applied in the growth chamber tests.

\begin{tabular}{ccc}
\hline Growth Chamber & Kind and Source of Radiation & $\begin{array}{c}\text { Distance between the Plant and } \\
\text { the Source of Radiation }(\mathbf{c m})\end{array}$ \\
\hline \multirow{2}{*}{ A } & $\begin{array}{c}20 \text { fluorescent lamps }(58 \mathrm{~W}) \text {-Philips } \\
+ \text { four light bulbs }(60 \mathrm{~W}) \text {-Philips }\end{array}$ & 65 \\
\hline \multirow{2}{*}{ B } & 18 fluorescent lamps $(58 \mathrm{~W})$-Philips \\
& +12 light bulbs $(75 \mathrm{~W})$-Paulmann & 55 \\
\hline
\end{tabular}

The selection of the radiation sources under these conditions with proper spectral characteristics of radiation was led with the use of spectroradiometric measurements. The distance between the fluorescent lamps, Philips bulb, Paulmann lamp and spectroradiometer's sensor amounted to $20 \mathrm{~cm}$ (Figures 1 and 2). In both chambers, radiation from fluorescent lamp from Philips company (58 W) was used. Moreover, in the A chamber, additional radiation originating from Philips company bulbs (60 W) was used, and in the B chamber radiation from halogen lamps of type PAR 30 rosé $(75 \mathrm{~W})$ from the Paulmann company was used. The temperature, air moisture, and length of a day and a night were the same in both chambers. In the studies, we used the day and night cycle occurring under natural conditions. The experiments were started under the conditions of a sunrise and sunset simulation, which occurred in Puławy $\left(51^{\circ} 24^{\prime} 46^{\prime \prime} \mathrm{N}, 21^{\circ} 58^{\prime} 00^{\prime \prime}\right.$ E) on 26 March when the length of day/night amounted to $12 \mathrm{~h}$ and $30 \mathrm{~min} / 11 \mathrm{~h}$ and $30 \mathrm{~min}$ (while for the longest day of the year-21 June-it amounted to $16 \mathrm{~h}$ and $38 \mathrm{~min} / 7 \mathrm{~h}$ and $22 \mathrm{~min}$ ), and at the end of vegetation the length of the day/night reached $15 \mathrm{~h}$ and $30 \mathrm{~min} / 8 \mathrm{~h}$ and $30 \mathrm{~min}$. For every following day, the length of the day was increasing and the length of the night was decreasing. During the whole period of experimentation, the air temperature was changing in the chambers respectively to the temperature occurring under natural conditions in Puławy in the months of the year following March 26, and thus in the beginning of the experiment the mean day/night temperature amounted to $7.5 / 2.5^{\circ} \mathrm{C}$, while in April it was $12 / 4{ }^{\circ} \mathrm{C}$, in May it was $19.4 / 7.8^{\circ} \mathrm{C}$, in June it was $24.0 / 10.0{ }^{\circ} \mathrm{C}$, and in July it was $25.9 / 11.3^{\circ} \mathrm{C}$. 


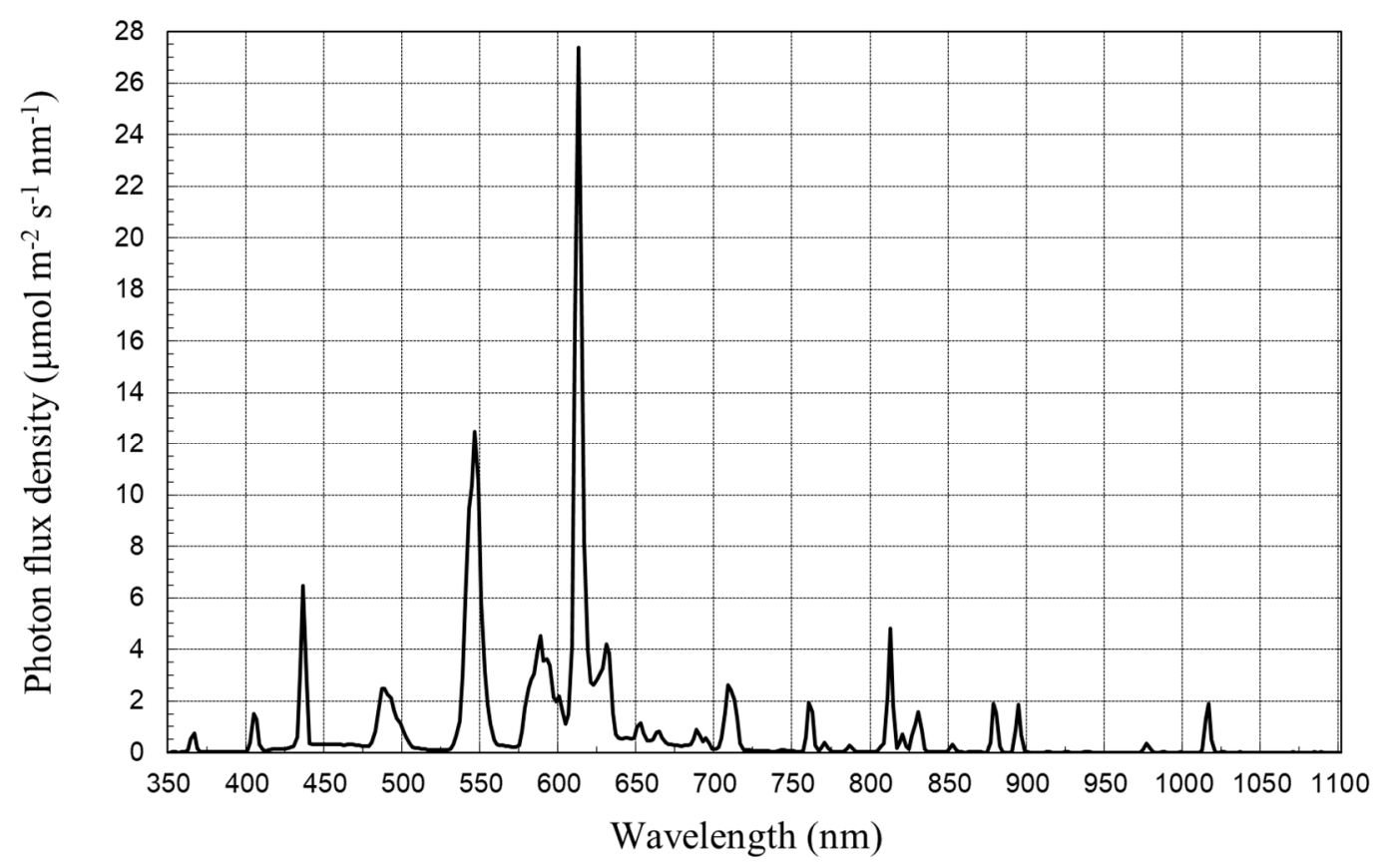

Figure 1. Spectral composition of fluorescent lamps' radiation for the Philips company (20 pieces) in HERAEUS growth chambers.

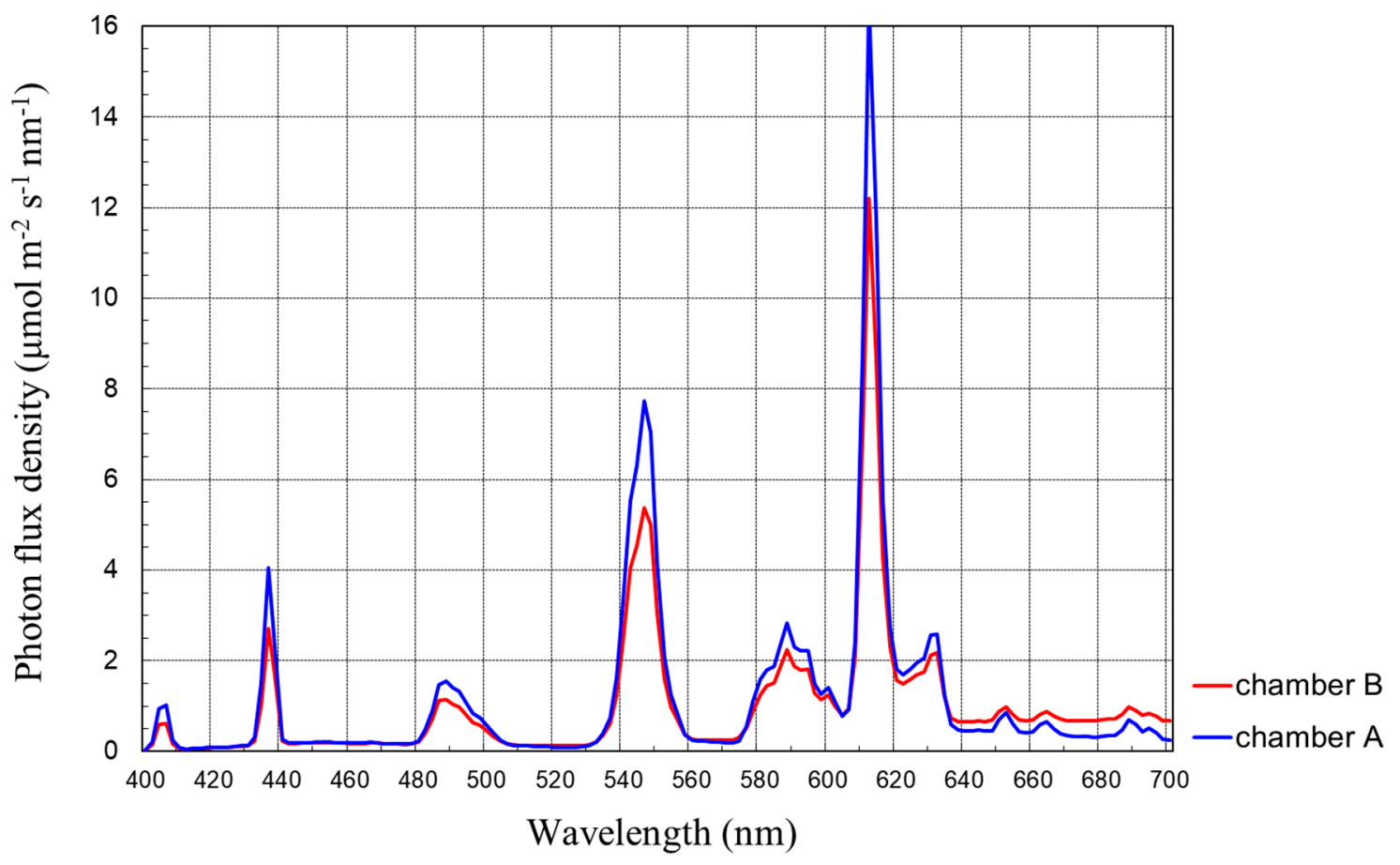

Figure 2. Spectral characteristics of the radiation in the photoactive range present in the growth chambers.

\subsection{Spectral Composition of Radiation}

The spectral composition of the radiation was measured with the use of a spectrometer LI-1800, which worked in the range of 350-1100 nm, with a half-width of $4 \mathrm{~nm}$. Radiation originating from the fluorescent lamps was characterized by the occurrence of many peaks (Figure 1). In the range of photosynthetic active radiation (400-700 nm), three main maxima occurred: about $430-440 \mathrm{~nm}$ 
(range violet-blue), 540-560 nm (green-yellow) and 610-620 nm (orange, as well as three smaller ones: 480-490 nm (blue-green), 580-590 nm (yellow) and about $630 \mathrm{~nm}$ (red) (Figures 1 and 2).

To obtain a similar amount of photosynthetic active radiation (PAR 400-700 nm) to reach the plants (the density of photon stream PAR was about $300 \mu \mathrm{mol} \mathrm{m}^{-2} \mathrm{~s}^{-1}$ ), fluorescent lamps, bulbs and lamps were placed at a differentiated distance under the plants (Table 1). The spectral characterization of PAR is presented in Figure 2.

The spectral composition of the Philips bulb and Paulmann halogen lamp radiation shows the significant participation of long-term radiation (Figure 3). These sources of radiation are characterized by an increase of irradiation as the wavelength increases from the range of violet to near infrared. However, the increase of radiation above $563 \mathrm{~nm}$ (in the range of yellow, orange and red) is considerably greater for Paulmann lamps than for Philips bulbs.

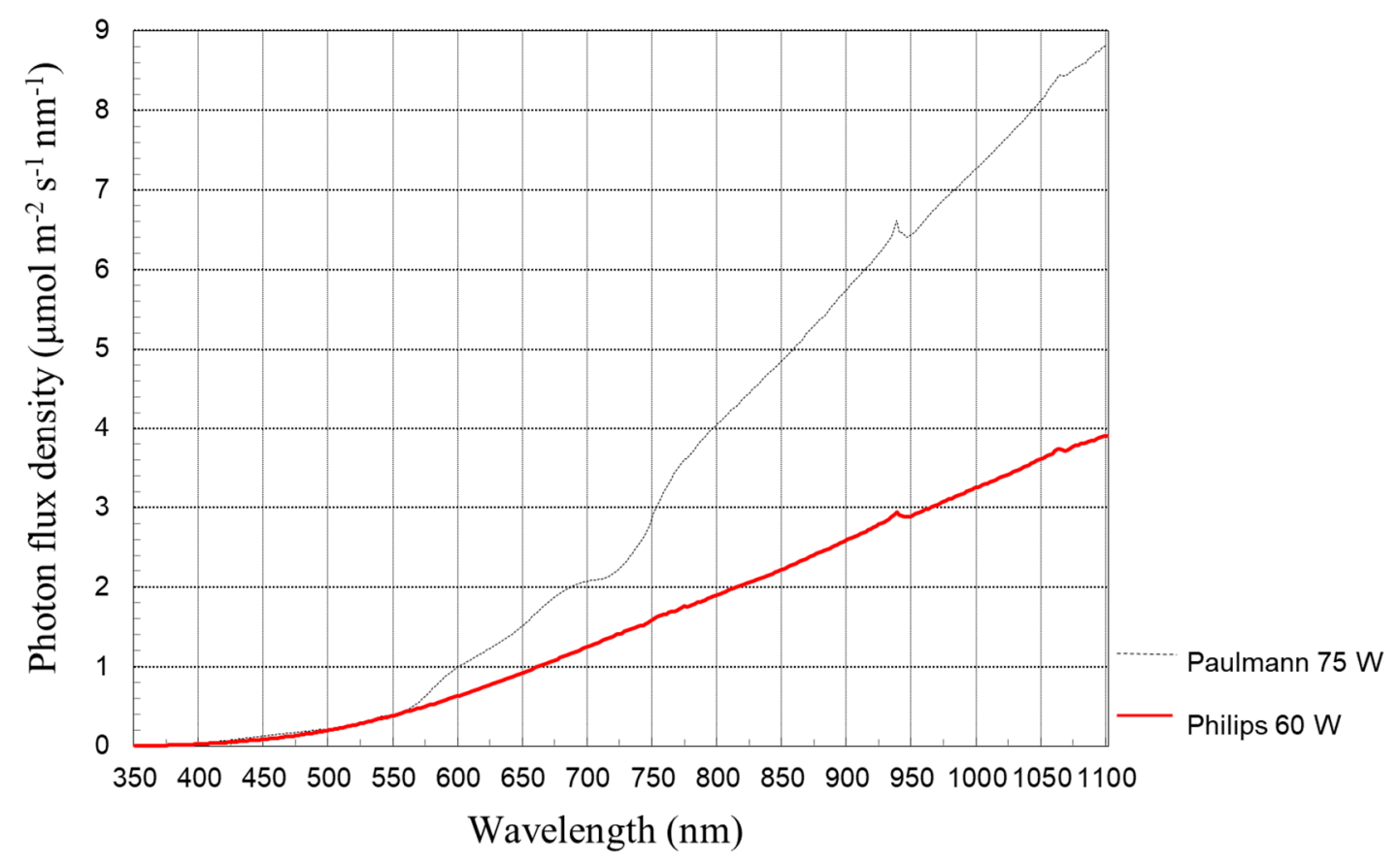

Figure 3. Spectral composition of the radiation of Philips light bulbs and lamps of the Paulmann type PAR30 rosé. Explanations: the distance of the sensor of a spectroradiometer from the source of radiation amounted to $20 \mathrm{~cm}$.

After the application of a properly chosen set of fluorescent lamps, bulbs and lamps, and a differentiated distance of plants from the source of radiation, we obtained various compositions of radiation in each chamber (Figure 4).

The Paulmann type PAR30 rosé lamps emitted radiation that was characterized by a big differentiation between the range of 600 and $700 \mathrm{~nm}$, considerably greater than that occurring in the radiation of the Philips fluorescent lamps. The use of lamps with different spectral compositions led to us obtaining the needed conditions of radiation, which showed a differentiated R/FR ratio in the particular chambers. The values of the R/FR ratio at the radiation used in the growth chambers are shown in Table 2. 


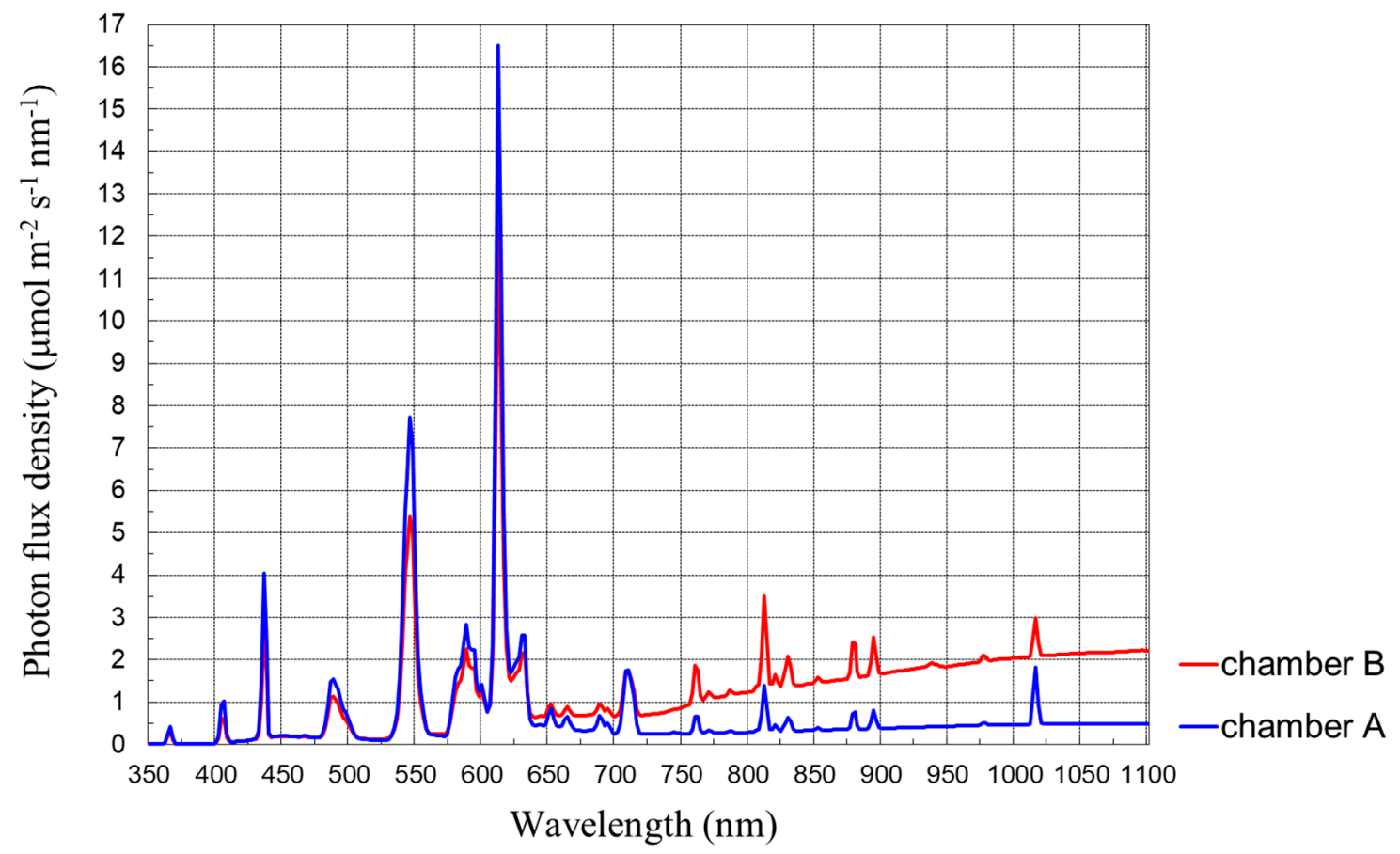

Figure 4. Spectral composition of the radiation in the growth chambers used in the experiment with spring barley.

Table 2. Values of the R/FR ratio in the radiation applied in the growth chambers.

\begin{tabular}{|c|c|}
\hline Growth Chamber & $\begin{array}{c}\mathrm{R} / \mathrm{FR} \\
(650-670 \mathrm{~nm} / 720-740 \mathrm{~nm})\end{array}$ \\
\hline A & 2.08 \\
\hline B & 1.02 \\
\hline
\end{tabular}

The integrated values of radiation in the selected spectral ranges used in the chambers are shown in Table 3. Radiation below $400 \mathrm{~nm}$ was similar in both chambers, whereas differences occurred for radiation above $400 \mathrm{~nm}$. The greatest radiation in the spectral ranges 400-499 and 500-599 $\mathrm{nm}$ occurred in chamber A, and it was a little smaller in chamber B. Meanwhile, the wavelength increased above $600 \mathrm{~nm}$, so the differences in radiation between both chambers were larger and larger; however, a smaller radiation occurred in the chamber $\mathrm{A}$ and a greater occurred in the B one.

The use of different sources of radiation caused very big differences in the amounts of radiation in the range of 700-1100 $\mathrm{nm}$, which is a considerable part of the radiation that is far red $(780-1400 \mathrm{~nm})$. The biggest radiation in this range occurred in chamber B, and a smaller one occurred in the A one. The differences in the amounts of radiation in the visible range (about 380-750 nm) between chambers were relatively small, especially in the range of short waves: violet, blue, green, yellow and orange. The greatest radiation values from the visible range occurred in chamber $\mathrm{A}$, and they were smaller for chamber B. In the growth and development of plants, the most important radiation is radiation from the photosynthetic active range-PAR. Radiation in the wavelength exceeding $700 \mathrm{~nm}$, especially long-wave radiation-near infrared (NIR, 700-1100 nm) - has a smaller effect on growth parameters because in this range both the transmission and reflection of radiation are very big in comparison to PAR, amounting in each case to more than $45 \%$. This results in plants' absorption of radiation in this range only reaching some percentages.

In Figure 5, the differences in the spectral composition of radiation in the growth chambers are visible(Figure 5). Greater differences occurred for the red and purple color (far red) (Figure 4, Table 2). 
Table 3. Characterization of the radiation in the chosen spectral ranges in the growth chambers.

\begin{tabular}{|c|c|c|}
\hline \multirow{2}{*}{ Description of Radiation } & \multicolumn{2}{|c|}{ Integrated Value $\left(\mu \mathrm{mol} \mathrm{m} \mathrm{m}^{-2} \mathrm{~s}^{-1}\right)$} \\
\hline & Chamber A & Chamber B \\
\hline \multicolumn{3}{|c|}{ Range } \\
\hline $350-399$ & 2 & 2 \\
\hline $400-499$ & 40 & 38 \\
\hline $500-599$ & 128 & 105 \\
\hline $600-699$ & 140 & 152 \\
\hline $700-799$ & 41 & 101 \\
\hline $800-899$ & 43 & 165 \\
\hline $900-999$ & 42 & 185 \\
\hline 1000-1099 & 53 & 215 \\
\hline 400-700 (PAR) & 308 & 295 \\
\hline $700-1100$ & 181 & 677 \\
\hline $350-1100$ & 489 & 963 \\
\hline \multicolumn{3}{|c|}{ Color } \\
\hline 380-429 (violet) & 5.3 & 4.9 \\
\hline 430-469 (blue) & 18.4 & 16.8 \\
\hline 470-499 (blue-green) & 17.8 & 16.6 \\
\hline 500-529 (green) & 4.5 & 4.7 \\
\hline 530-559 (green-yellow) & 69.4 & 61.0 \\
\hline 560-589 (yellow) & 25.4 & 23.4 \\
\hline 590-619 (orange) & 101.4 & 94.8 \\
\hline $620-699$ (red) & 59.7 & 73.5 \\
\hline 700-759 (purple) & 28.0 & 54.1 \\
\hline
\end{tabular}

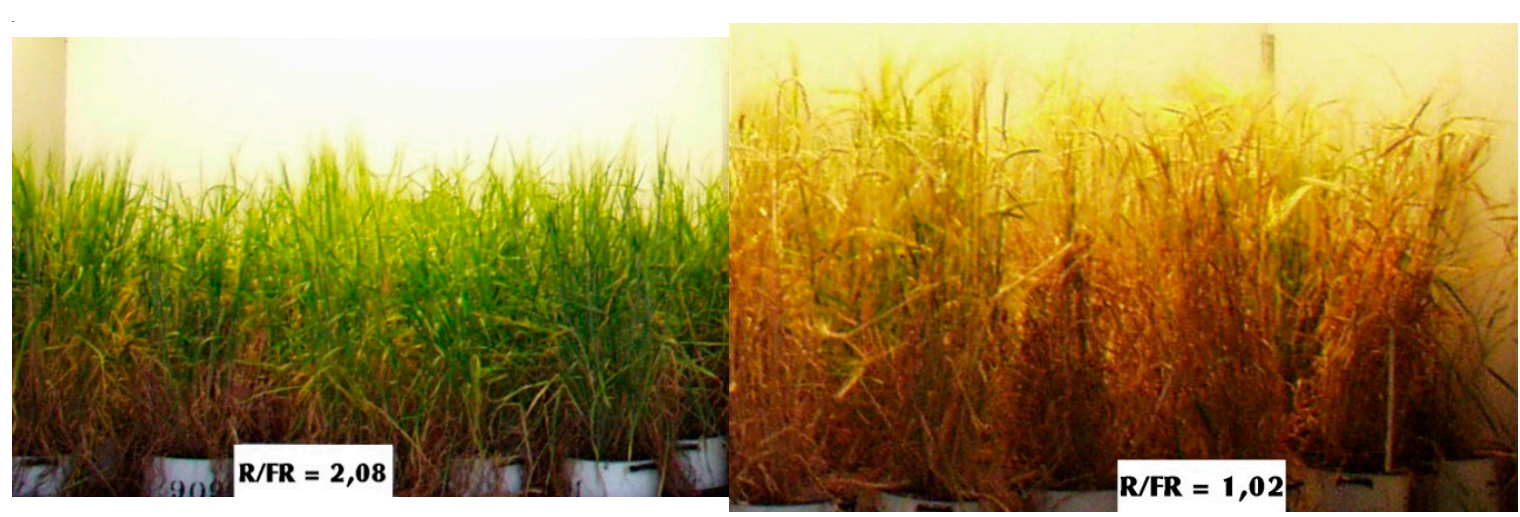

(a) chamber A

(b) chamber B

Figure 5. Spectral conditions in the growth chambers.

The radiation in the ranges of 620-699 and 700-759 $\mathrm{nm}$ was decidedly lower in chamber $\mathrm{A}$ than in chamber B. This difference was caused by the very low emission of fluorescent lamps in these ranges of radiation and, at the same time, the very high emission of Paulmann halogen lamps in the longwave part of the spectrum.

In the range of radiation of $650-750 \mathrm{~nm}$, one high pick with a maximum at $710 \mathrm{~nm}$ occurred, as well as four lower picks at 653, 666, 688 and 695 nm (Figure 6). 


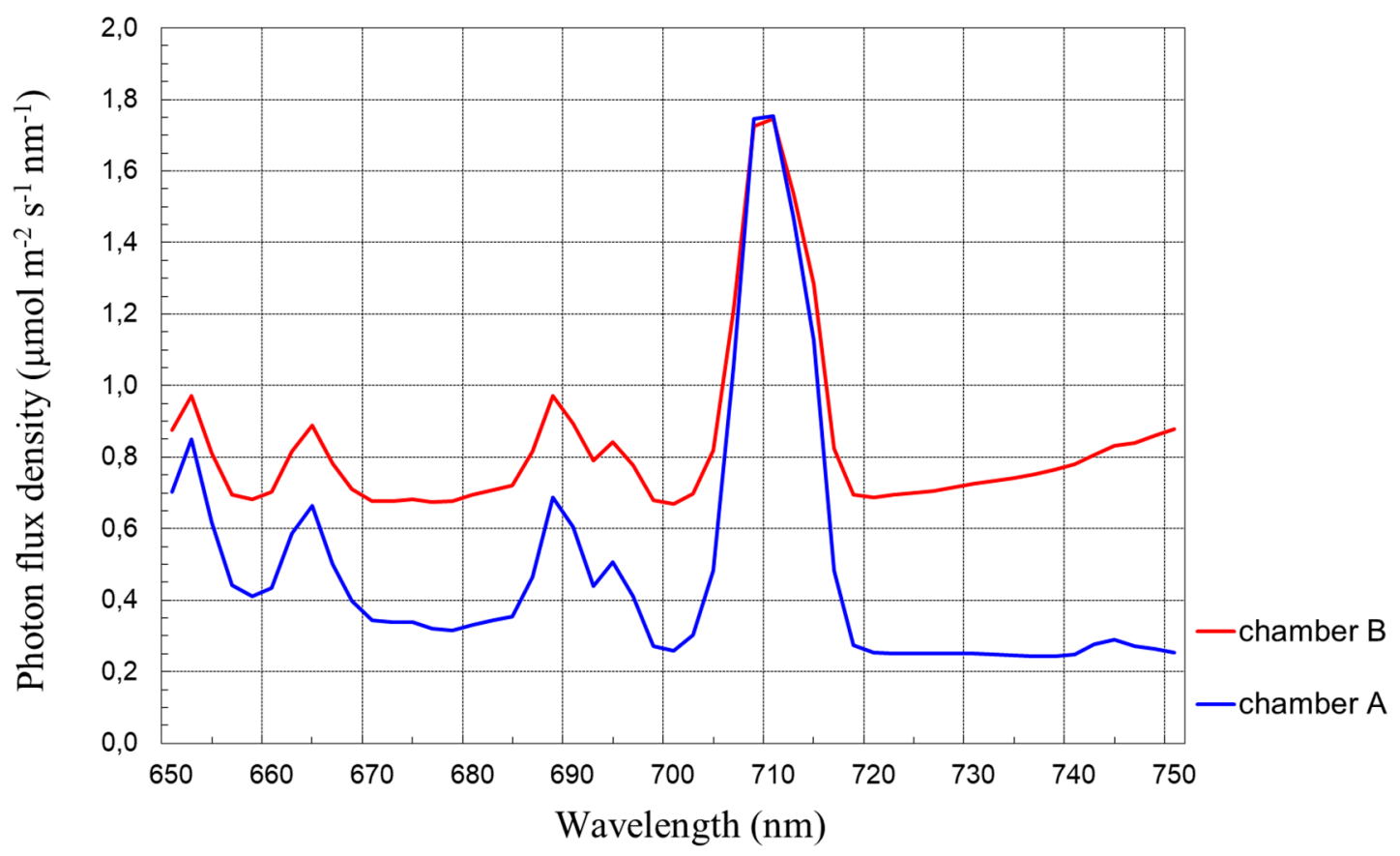

Figure 6. Characteristics of the radiation in the growth chambers in the range of red and far red.

\subsection{Research Material}

A subject of the study was spring barley cv. Rastik. Five grains of barley were sown in every Mitscherlich pot and filled with $3 \mathrm{~kg}$ of substrate based on high peat (sphagnum peat). The $\mathrm{pH}_{\mathrm{H} 2 \mathrm{O}}$ of this substrate was 5.5-6.5, and the concentrations of $\mathrm{N}, \mathrm{P}\left(\mathrm{P}_{2} \mathrm{O}_{5}\right)$ and $\mathrm{K}\left(\mathrm{K}_{2} \mathrm{O}\right)$ were in a ratio of 14:16:18, respectively. It also contained some amounts of $\mathrm{MgO}$, as well as microelements: $\mathrm{Fe}, \mathrm{Mn}, \mathrm{Cu}$, $\mathrm{Zn}$, Mo and B. The dry mass of the substrate amounted to $35 \%$, and the organic substance amounted to $85 \%$. On the third day after emergence, plants were tinned, and one plant was left in each pot. In both growth chambers, 24 Mitscherlich pots were placed.

Measurements of photosynthesis, the intracellular concentration of $\mathrm{CO}_{2}$ and stomatal conductance were performed with the use of the LI 6400 (LI-COR). The photosynthetic activity of plants was measured two times: first, during the phase of 7 leaves (measurement on the sixth leaf) and, second, during the phase of the fully developed flag leaf of barley (measurement on the flag leaf).

Transpiration was determined with the use of water use efficiency (WUE) as an indicator of the water efficiency at photosynthesis, which characterizes gas exchange in the assimilation organs:

$$
\mathrm{WUE}=\mathrm{Pn} / \mathrm{E}
$$

where: Pn—photosynthesis $\left(\mu \mathrm{mol} \mathrm{CO} \mathrm{CO}^{-2} \mathrm{~s}^{-1}\right)$ and E-transpiration $\left(\mathrm{mmol} \mathrm{H}_{2} \mathrm{O} \mathrm{m}^{-2} \mathrm{~s}^{-1}\right)$.

The number of stomata was determined using an optical microscope (Nikon company) at a 400-fold enlargement in the field of view.

The chlorophyll content in the leaves was determined with the use of the optical device HYDRO $\mathrm{N}$-tester (Minolta 502), which measures the difference between the absorption of radiation at wavelength $650 \mathrm{~nm}$ (maximum absorption of radiation in the range of red) and $940 \mathrm{~nm}$ (radiation transmitted by the leaf tissue). The average chlorophyll content was counted on the basis of 30 properly performed measurements on the leaves of the same plant. The measurement result is given in SPAD units (Soil Plant Analysis Development) on a scale from 1 to 800.

The average values of the studied plant features were compared with the statistical program STATGRAPHYCS Plus v. 2.1 for Windows with the use of a multiple comparison test (Multiple Range Tests). 


\section{Results}

\subsection{Photosynthesis Efficiency}

The photosynthesis efficiency in the phases of the seventh and flag barley leaves, which grew in chamber A (with a high R/FR ratio), was significantly higher than for plants growing in chamber $\mathrm{B}$, in which the R/FR ratio was lower (Figure 7). There was also a difference in the photosynthesis between the tested leaves because flag leaves showed a decidedly greater intensity than the sixth leaves. However, at the flag leaf phase, a greater increase of photosynthesis efficiency was found in chamber B than in A when compared to the earlier seventh leaf phase.

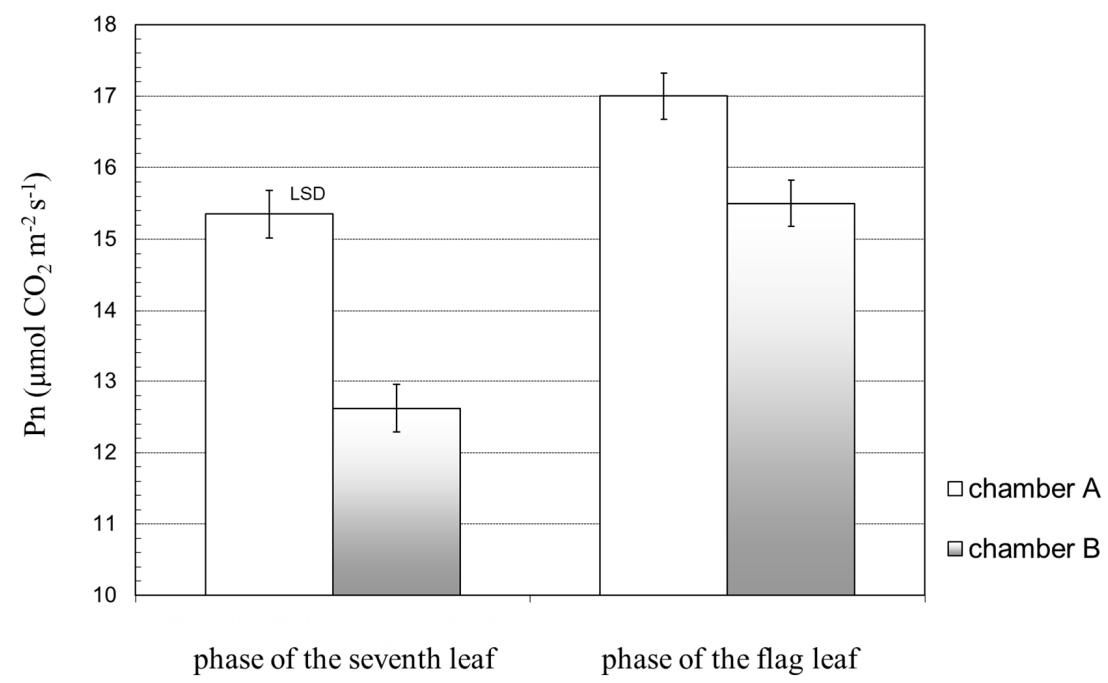

Figure 7. Efficiency of photosynthesis depending on the developmental phase of spring barley and the $\mathrm{R} / \mathrm{FR}$ ratio in the growth chambers.

\subsection{Intracellular Concentration of $\mathrm{CO}_{2}$}

Spring barley plants growing in chamber $\mathrm{A}$, where radiation conditions with the $\mathrm{R} / \mathrm{FR}$ ratio amounted to 2.08, showed a higher intracellular concentration of $\mathrm{CO}_{2}$ than in chamber $\mathrm{B}$, where the R/FR ratio was 1.02 (Figure 8). Otherwise, flag leaves, especially those which were growing in chamber $\mathrm{A}$, showed a greater intracellular concentration of $\mathrm{CO}_{2}$ than sixth leaves.

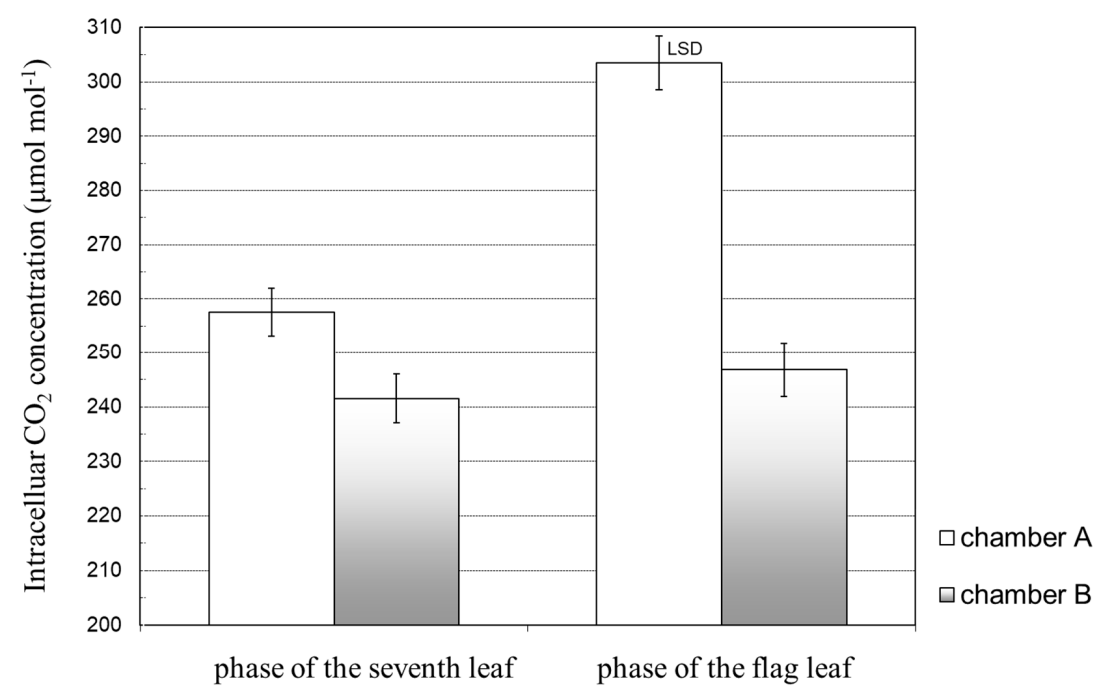

Figure 8. Intracellular $\mathrm{CO}_{2}$ concentration in the leaves of spring barley depending on the radiation conditions in the growth chambers and the developmental phase of the plants. 


\subsection{Transpiration and Water Use Efficiency Index (WUE)}

Measurements of the water transpiration showed a considerably lower use of water by the plants growing under conditions with a lower (chamber B) than with a higher (chamber A) R/FR ratio (Figure 9). Moreover, the performed studies showed that flag leaves transmitted more water than sixth leaves.

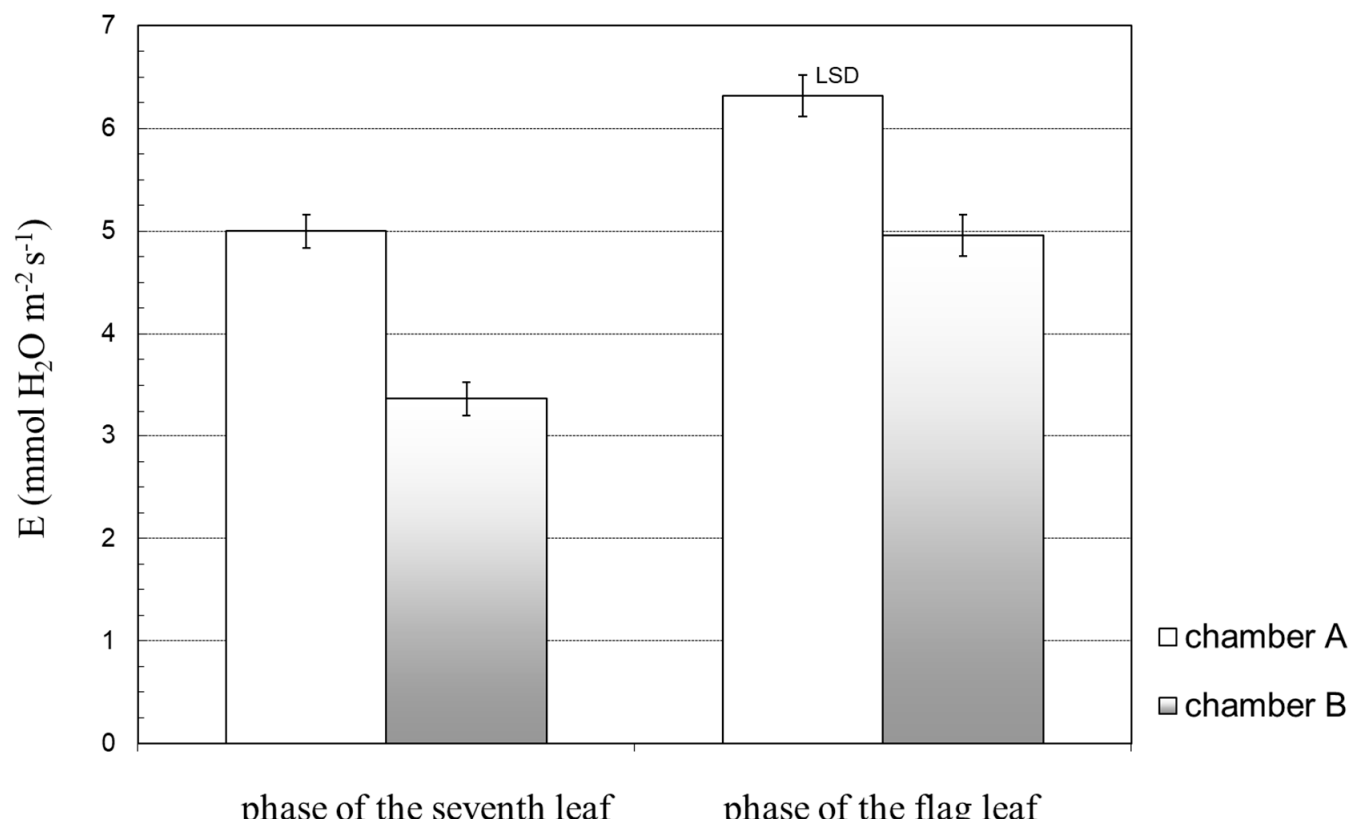

Figure 9. Transpiration of water by the spring barley leaves depending on the radiation conditions in the growth chambers and the developmental phase of the plants.

Greater values of the WUE index in the barley leaves characterized the plants growing at a lower R/FR ratio, whereby flag leaves showed a considerably lower effectivity in their water use than sixth leaves (Figure 10).

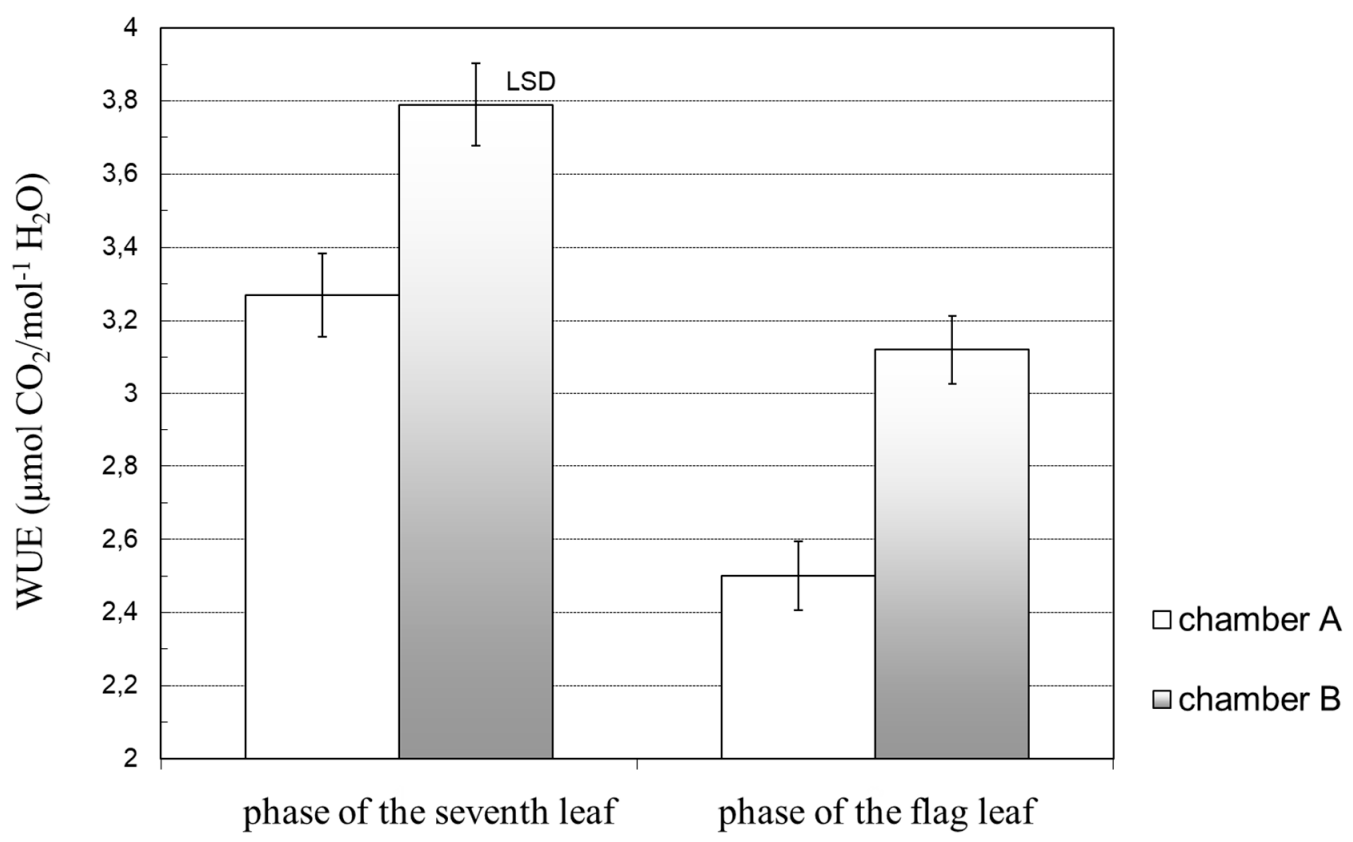

Figure 10. WUE index of spring barley leaves depending on the radiation conditions in the growth chambers and the plant development. 


\subsection{Stomatal Conductance and Number of Stomata.}

Spring barley plants growing under conditions with a two-fold higher R/FR ratio conducted considerably more water (Figure 11). Furthermore, the stomata of flag leaves conducted more water than those of sixth leaves, especially in chamber A.

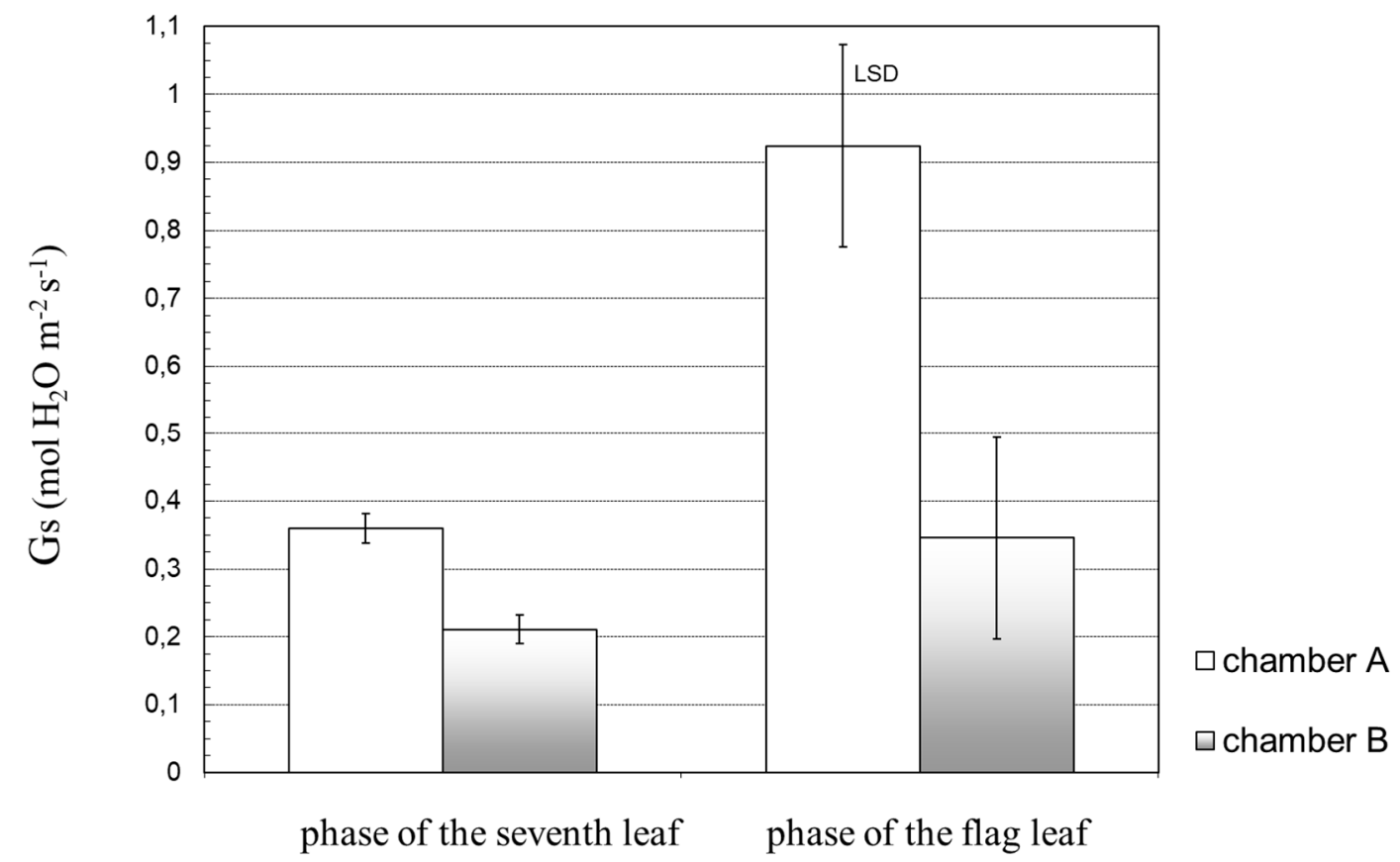

Figure 11. Stomatal conductance of the spring barley leaves depending on the radiation in the growth chambers.

Measurements of the stomata number at the seventh leaf phase (on the sixth leaf) and in the flag leaf stage on the upper and lower side of the flagship leaf were performed. It was found that barley plants growing under conditions with a low share of FR formed more stomata on both the upper and lower side of leaves than plants growing under conditions with a high share of FR-chamber $B$ (Figures 12-14). The sub-flag leaves of barley cultivated in the chamber with a high R/FR ratio had about three stomas more than the plants in the chamber with a high share of FR (Figures 12 and 13).

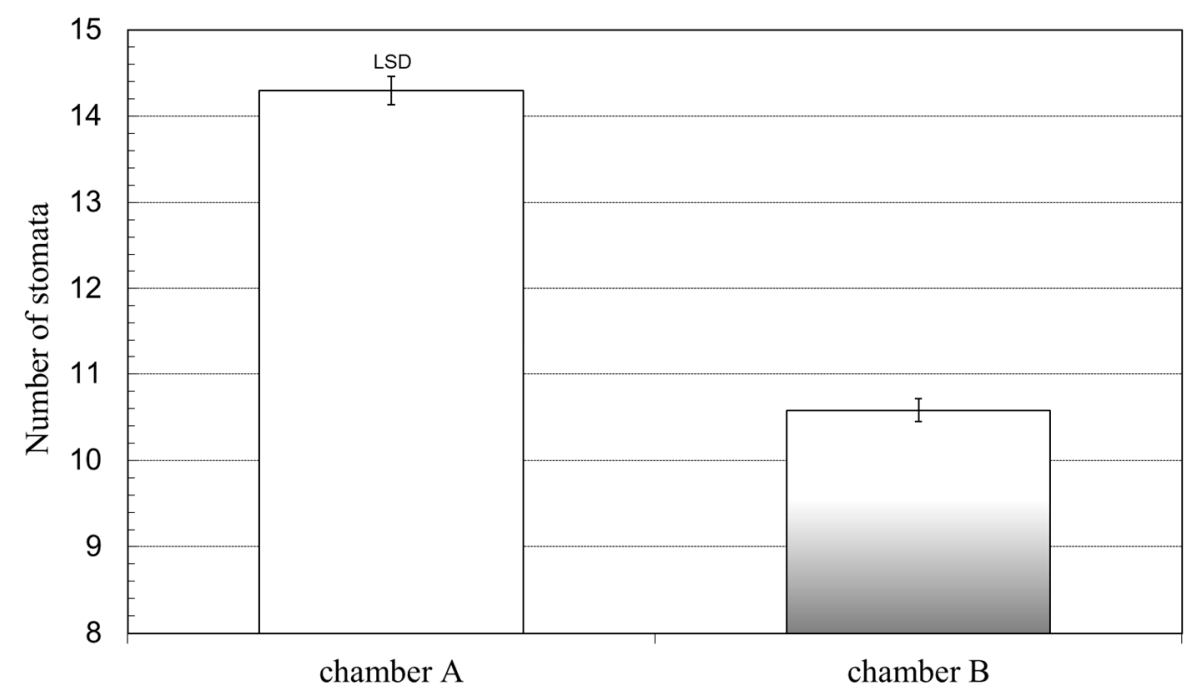

Figure 12. The number of stomata on the upper surface of sub-flag leaves depending on the R/FR ratio in the chamber. 


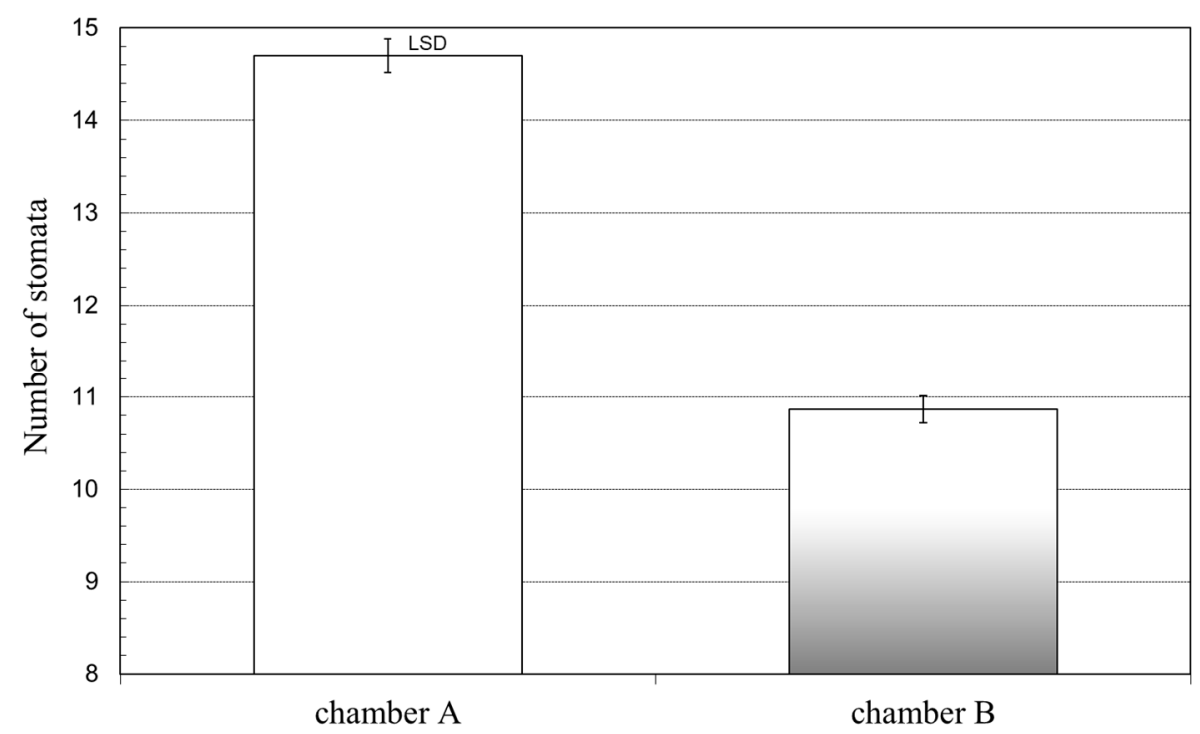

Figure 13. The number of stomata on the bottom surface area of flag leaves depending on the R/FR ratio in the chamber. Explanations-number of stomata in the microscope field of view at a 400× enlargement.

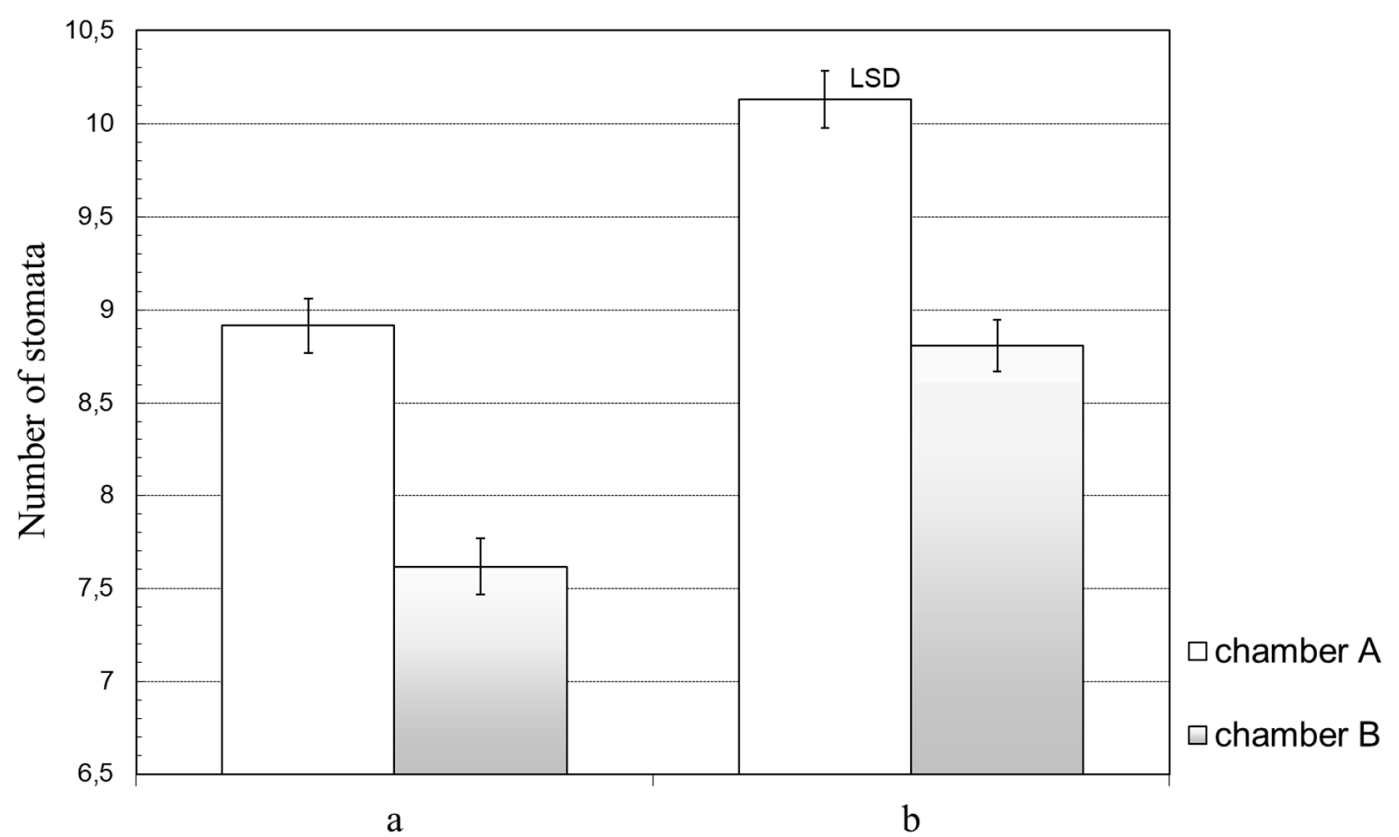

Figure 14. Number of stomata on the sixth leaf of spring barley. Explanations-number of stomata in the microscope field of view at a 400× enlargement. (a) - upper surface of the leaf. (b) - lower surface of the leaf.

Observations of the sixth leaf of spring barley also showed a lower number of stomata on the upper and lower sides of the leaf areas of plants growing under conditions with a decreased share of FR when compared to a reduced share of FR (Figure 14).

\subsection{Chlorophyll Content in the Leaves}

Measurements of chlorophyll were performed on the sixth and seventh leaves of barley. At a decreased amount of FR, plants produced more chlorophyll (more SPAD units) than plants growing with a higher amount of this light (Figure 15). 


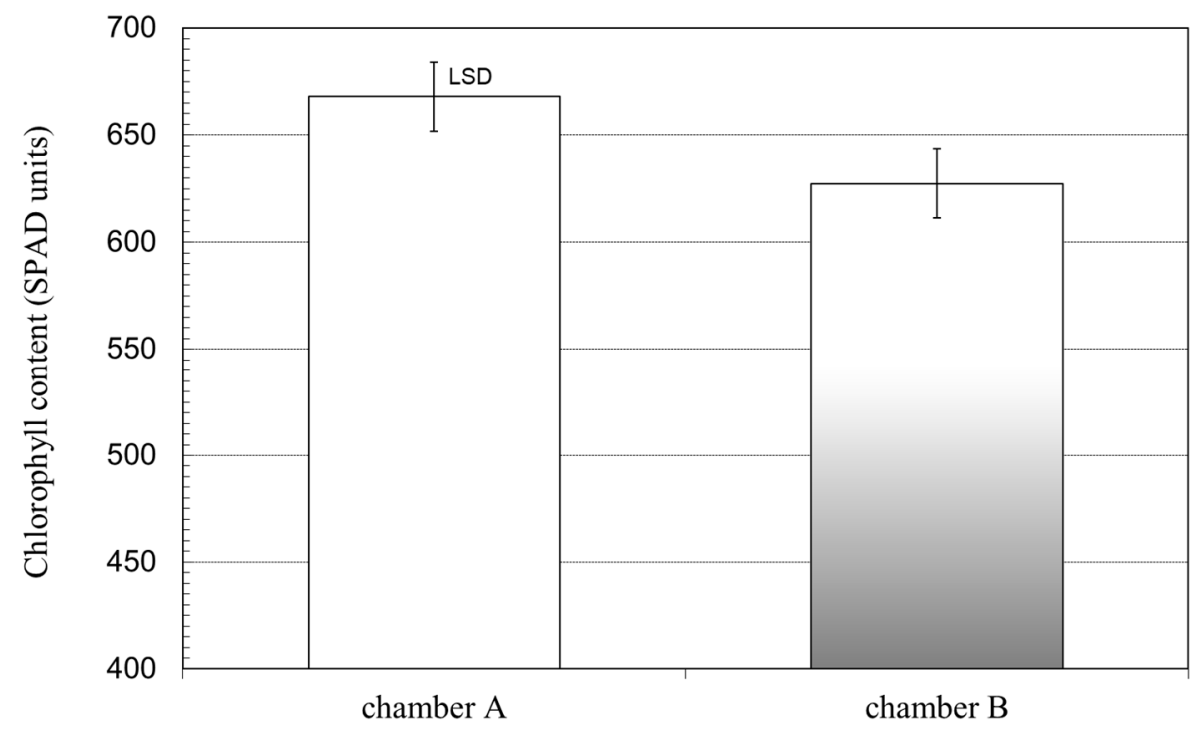

Figure 15. Content of chlorophyll in the sixth and seventh leaves.

\section{Discussion}

The studies conducted on the effect of far red and red showed the significant effect of radiation conditions on the physiological processes of plants. The obtained results fully proved that barley plants responded very strongly to the spectral composition of radiation [12]. Among the tested species of cereal plants, the strongest response to an enlarged share of radiation in the FR range was shown by spring wheat [12]. The studies conducted by authors on spring barley also indicated that this species belongs to the group of plants showing a strong response to relations between R and FR. Undoubtedly, the observed cereal's response fully deserves to be named as an SAS reaction occurring in plants growing in dense stands, although there was a lack of competitive conditions. These aspects are the results of radiation conditions, which invoke certain physiological processes, and which are, to a great extent, determined by the photosynthetic effect of gas exchange and $\mathrm{CO}_{2}$ assimilation. The volume of gas exchange that consists of photosynthesis, stomatal respiration and the WUE index is dependent, among others, on spectral composition and radiation intensity [35]. Plant responses such as the shoot elongation, height of plant and internodes are more connected to the spectral composition than to the radiation intensity. A very similar amount of radiation was used in the studies conducted in the growth chambers, so it can be expected that the main differential element of the plant behavior was the spectral composition of the radiation. The plant responses under the different radiation conditions were respective processes connected to gas exchange and water management.

Photosynthesis efficiency, expressed as the $\mathrm{CO}_{2}$ gas exchange of sixth and flag leaf of barley, showed significantly higher values in objects with a high R/FR ratio than in those with a low R/FR ratio. This indicates that plants that were growing under radiation conditions with a relatively low R/FR ratio led a more economical $\mathrm{CO}_{2}$ consumption. Similarly, for tobacco irradiated with a low R/FR ratio, the net assimilation of $\mathrm{CO}_{2}$ was lower than after irradiation with a high $\mathrm{R} / \mathrm{FR}$ ratio [30]. Sleeman et al. also reported about the greater photosynthesis efficiency after the use of radiation with a high R/FR ratio $=10.0$ [35]. The photosynthesis efficiency measured by $\mathrm{CO}_{2}$ gas exchange in Mercurialis annua-a plant from the Euphorbiaceae family - under radiation conditions with an R/FR ratio $=1.1-1.4$ was lower, similar to the experiment with wheat [36] and to the present experiment with barley (chamber B). Photosynthesis efficiency is a physiological process that is very sensitive to stress conditions. Under an optimal soil moisture, $\mathrm{CO}_{2}$ was assimilated by grasses to a considerably greater degree than under a water deficit [37].

Besides the energy expressed as the amount of absorbed photons, the second very important factor that enables the course of photosynthesis is the supply of $\mathrm{CO}_{2}$, which is the intracellular concentration of carbon dioxide $\left(\mathrm{CO}_{2}\right)$. The intracellular concentration of carbon dioxide was considerably higher in 
the wheat [36] and barley, which grow under radiation conditions with a high R/FR ratio. The obtained result means that plants growing in chambers with a high R/FR ratio had better access to carbon dioxide, which caused the increase of their biomass production. The increase of starch production in the leaves of tomato was reported by Czarnowski and Starzecki, among others [38].

Another physiological aspect is water management. Barley growing in chambers with a lower R/FR ratio showed a considerably lower consumption of water than plants growing at a high ratio. The response of wheat plants was similar, although less spectacular [36]. On this basis, it can be assumed that these responses are undoubtedly a manifestation of adaptation of plants growing under radiation conditions with a low R/FR ratio to restrict water consumption with regards to expected competition or droughts because a lower R/FR ratio occurs in a dry atmosphere and a higher one occurs in an atmosphere with a lot of moisture [11]. Similar results were obtained in relation to the transpiration of cotton and Abutilon theophrasti plants, which also showed a lower use of water at a low $\mathrm{R} / \mathrm{FR}$ ratio than under radiation with a higher value of this ratio [39,40]. The mechanisms by which a phytochrome influences the water economy may be more or less complicated [41-43]. Some recent reports showed that the phytochrome increased tolerance to a high evaporative demand [44] and that phytochromes A and B could modulate drought stress responses [45].

A synthetic indicator that describes water transpiration from plants and photosynthesis efficiency is water use efficiency (WUE), also known as the index of water efficiency under photosynthesis. It characterizes the gas exchange in the assimilation organs and water consumption. In the conducted studies with the velvet leaf plants, a small increase of WUE values treated with a high R/FR ratio was obtained, but the differences were too little to be significant [35]. Considerably higher WUE values were obtained for barley plants growing at a radiation with a low R/FR ratio when compared to a radiation with a higher ratio. These results indicated that in competitive conditions (with a low R/FR ratio), the efficiency of water consumed under barley photosynthesis was considerably higher than in non-stressful conditions (with a high R/FR ratio). In the present studies, higher WUE values also occurred for barley plants subjected to drought stress. Similar results were obtained by Staniak with four species of fodder grasses under competitive conditions connected with water deficit [37].

Barley conducted water to a much greater extent under conditions with a high than with a low $\mathrm{R} / \mathrm{FR}$ ratio. The obtained stomatal conductance results indicate that plants growing under radiation conditions with a low share of FR (which shows a lack of competition) conducted considerably more water than plants growing under conditions with a higher share of radiation from this range, i.e., under competitive conditions. Very similar results concerning the stomatal conductance were obtained by Sleeman et al. [35] with Mercurialis annua plants during experiments with the same conditions of radiation and by Staniak [37] with plants growing under water shortage.

The size of the R/FR ratio may regulate the number of stomata. In previous studies, Doroszewski [36] found that different spectral compositions caused the number of stomata formed by the wheat to be dependent on the value of the R/FR ratio, as was the case with barley. Plants receiving radiation with a high R/FR ratio produced considerably more stomata on both sides of the leaves than those growing at a low ratio. Close to similar effects were reported by Kasperbauer and Peaslee [31]. In their experiment with tobacco, the number of stomata on both sides of the leaves was lower for plants radiated with a low R/FR ratio than for plants treated with a high ratio. The results concerning the number of barley and wheat stomata [36] indicate the plants' adaptation to the competitive conditions. An increase of the stomata number prevents excessive transpiration. Competitive conditions contribute to an insufficient water supply, so an adaptive response of plants consists not only in closing the stomata but also in limiting their number. In the unfavorable light (chamber B), the number of stomata was decidedly lower because barley behaved as if it grew under typical competitive conditions. The response of barley plants to the spectral composition of the radiation clearly indicated their adaptation to the light conditions.

Another element that indicated a differentiated response to the spectral composition of radiation was the chlorophyll content. Both wheat [36] and, in this study, barley treated with a high R/FR ratio 
were characterized by a higher chlorophyll concentration than plants submitted to radiation with a low R/FR ratio.

From the spectral-radiometric measurements performed in the outdoor positions [11], it appears that the R/FR ratio in the solar radiation is close to 1 , while in the dense cereal stands it can be lower than 0.07 [36]. The R/FR ratio has a significant effect on photochromic reactions, which have a considerable effect on the development and yielding of plants. Phytochrome is a photoreceptor responsible for the registration of changes in radiation (solar or artificial). It belongs to the family of photoreceptors, which regulate the plant development in response to environmental radiation. Phytochrome reactions are very important during the whole ontogenesis, starting with seeds' germination, de-etiolation by the growth of a seedling, the detection of a neighboring plant, the reaction of avoidance of green seedlings' shading and the induction of reproductive behavior. The basic function of a phytochrome is the perception of R/FR radiation, which, after the signal has been reached (such as these wavelengths), starts the proper metabolic pathways, which allow for the induction of the mechanisms ensuring the optimal growth and development of plants. Smith [4] put forward a hypothesis about the perception of the R/FR ratio as the fundamental function of a phytochrome. Studies conducted with spring barley fully supported this hypothesis.

The information obtained on the environment in the form of radiation intensity and spectral composition are transmitted by the phytochrome, which regulates many metabolic changes and, respectively, effects on the plant morphology, ensuring that the expected competition is met. The results of the performed measurements under artificial conditions mean that during the whole plant development, physiological processes, e.g., the decrease of stomatal conductance, transpiration and the production of a lower number of stomata, were directed to a final effect-the maximization of adjustment processes in response to the existing conditions of radiation and to survival under conditions of probable stress connected with a lack of water.

The conducted research, which had the character of a model, led to the evaluation of the great importance of plants' neighborhood and proximity. The need to ensure a certain distance between plants (plant spacing) is particularly important, not only because of the availability of nutrients. It should be underlined that the observed changes on plants' physiology were not the result of competition but only their earlier preparation for it. This feature may be explained by the existence of a stimulus in the form of radiation with an increased share of FR, which signals the possibility of the occurrence of potential competition.

\section{Conclusions}

In this study, we observed a significant differentiation of the spring barley response under changing radiation conditions. The value of the R/FR ratio had an effect on the physiological processes in plants. Barley, which grew under conditions with a low R/FR ratio of radiation, was characterized by a low efficiency of net photosynthesis, lower number of stomata, and lower transpiration of water and chlorophyll concentration in leaves. These plants showed a decreased water conductivity and intracellular $\mathrm{CO}_{2}$ concentration, as well as a high index of water efficiency when compared to plants grown under conditions with a high ratio of this radiation range. Slowing down the physiological processes was directed toward an expected competition, and all efforts connected with plant functioning were directed toward surviving adverse radiation conditions with a minimum use of energy and water.

Author Contributions: Conceptualization, A.D.; methodology, A.D. and T.D.; validation, T.D. and A.P.; formal analysis, A.D., T.D. and A.P.; investigation, A.D., T.D. and A.P.; resources, A.D., T.D. and A.P.; writing-original draft preparation, A.D.; writing-review and editing, A.D., T.D. and A.P.; visualization, A.P.; supervision, T.D. and A.P.; project administration, A.D.; funding acquisition, A.D. All authors have read and agreed to the published version of the manuscript.

Funding: This study was supported with funds from the Polish Ministry of Agriculture and Rural Development, for grant: KS. zc. 42.1.2020 "Agricultural Drought Monitoring System".

Conflicts of Interest: The authors declare no conflict of interest. 


\section{References}

1. Ballaré, C.L.; Scopel, A.L.; Sánchez, R.A. Far-red radiation reflected from adjacent leaves: An early signal of competition in plant canopies. Science 1990, 247, 329-332. [CrossRef] [PubMed]

2. Smith, H.; Whitelam, G.C. The shade avoidance syndrome: Multiple responses mediated by multiple phytochromes. Plant. Cell Environ. 1997, 20, 840-844. [CrossRef]

3. Smith, H. Phytochromes and light signal perception by plants: An emerging synthesis. Nature 2000, 407, 585-591. [CrossRef] [PubMed]

4. Smith, H. Light quality, photoperception and plant strategy. Annu. Rev. Plant. Physiol. 1982, 33, 481-518. [CrossRef]

5. Ballaré, C.L. Keeping up with the neighbors: Phytochrome sensing and other signalling mechanisms. Trends Plant. Sci. 1999, 4, 97-102. [CrossRef]

6. Ballaré, C.L.; Sánchez, R.A.; Scopel, A.L.; Casal, J.J.; Ghersa, C.M. Early detection of neighbor plants by phytochrome perception of spectral changes in reflected sunlight. Plant. Cell Environ. 1987, 10, 551-557.

7. Ballaré, C.L.; Scopel, A.L.; Sánchez, R.A. Foraging for light: Photosensory ecology and agricultural implications. Plant. Cell Environ. 1997, 20, 820-825. [CrossRef]

8. Smith, H.; Casal, J.J.; Jackson, G.M. Reflection signals and the perception by phytochrome of the proximity of neighboring vegetation. Plant. Cell Environ. 1990, 13, 73-78. [CrossRef]

9. Górski, T. Germination of seeds in the shadow of plants. Physiol. Plant. 1975, 34, 342-346. [CrossRef]

10. Smith, H.; Morgan, D.C. The spectral characteristics of the visible radiation incident upon the surface of the earth. In Plants and Daylight Spectrum; Smith, H., Ed.; Academic Press: London, UK; New York, NY, USA; Toronto, ON, Canada; Sydney, Australia; San Francisco, CA, USA, 1981.

11. Doroszewski, A.; Górski, T.; Kozyra, J. Atmospheric moisture controls the far red irradiation: A probable impact on the phytochrome. Int. Agrophys. 2015, 29, 283-289. [CrossRef]

12. Górski, T.; Doroszewski, A.; Górska, K. Photomorphogenic impact of neighbouring plants on spring wheat tillering. Zesz. Probl. Post. Nauk Roln. 1991, 396, 43-46.

13. Aphalo, P.J.; Ballaré, C.L.; Scopel, A.L. Pant-plant signalling, the shade avoidance response a nd competition. J. Exp. Bot. 1999, 50, 1629-1634. [CrossRef]

14. Vandenbussche, F.; Pierik, R.; Millenaar, F.F.; Voesenek, L.A.C.J.; Van der Straeten, D. Reaching out of the shade. Curr. Opin. Plant. Biol. 2005, 8, 462-468. [CrossRef] [PubMed]

15. Franklin, K.A.; Whitelam, G.C. Phytochromes and shade-avoidance responses in plants. Ann. Bot. 2005, 96, 169-175. [CrossRef] [PubMed]

16. McNellis, T.W.; Deng, X.-W. Light control of seedling morphogenetic pattern. Plant. Cell 1995, 7, 1749-1761. [PubMed]

17. Yanovsky, M.J.; Casal, J.J.; Whitelam, G.C. Phytochrome A, phytochrome B and HY4 are involved in hypocotyl growth responses to natural radiation in Arabidopsis: Weak de-etiolation of phyA mutant under dense canopies. Plant. Cell Environ. 1995, 18, 788-794. [CrossRef]

18. Casal, J.J.; Kendrick, R.E. Impaired phytochrome-mediated shade-avoidance responses in the aurea mutant of tomato. Plant. Cell Environ. 1993, 16, 703-710. [CrossRef]

19. Kang, C.Y.; Lian, H.L.; Wang, F.F.; Huang, J.R.; Yang, H.Q. Cryptochromes, phytochromes, and COP1 regulate light-controlled stomatal development in Arabidopsis. Plant. Cell 2009, 21, 2624-2641. [CrossRef]

20. Aukerman, M.J.; Hirschfeld, M.; Wester, L.; Weaver, M.; Clack, T.; Amasino, R.M.; Sharrock, R.A. A deletion in the PHYD gene of the Arabidopsis Wassilewskaja ecotype defines a role for phytochrome D in red/far-red light sensing. Plant. Cell 1997, 9, 1317-1326.

21. Devlin, P.F.; Patel, S.R.; Whitelam, G.C. Phytochrome E influences internode elongation and flowering time in Arabidopisis. Plant. Cell 1998, 10, 1479-1487. [CrossRef]

22. Franklin, K.A.; Praekelt, U.; Stoddart, W.M.; Billingham, O.E.; Halliday, K.J.; Whitelam, G.C. Phytochromes B, D and E act redundantly to control multiple physiological responses in Arabidopsis. Plant. Physiol. 2003, 131, 1340-1346. [CrossRef] [PubMed]

23. Kasperbauer, M.J.; Karlen, D.L. Light-mediated bioregulation of tillering and photosynthate partitioning in wheat. Physiol. Plant. 1986, 66, 159-163. [CrossRef]

24. Kasperbauer, M.J. Far-red reflection from green leaves and effects on phytochrome-mediated assimilate partitioning under field conditions. Plant. Physiol. 1987, 85, 350-354. [CrossRef] [PubMed]

25. Casal, J.J.; Smith, H. The function, action and adaptive significance of phytochrome in light-grown plants. Plant. Cell Environ. 1989, 12, 855-862. [CrossRef] 
26. Kasperbauer, M.J. Spectral distribution of light in a tobacco canopy and effects of end-of-day light quality on growth and development. Plant. Physiol. 1971, 47, 775-778. [CrossRef]

27. Brown, C.S.; Schuerger, A.C.; Sager, J.C. Growth and photomorphogenesis of pepper plants under red light-emitting diodes with supplemental blue or far-red lighting. J. Am. Soc. Horticult. Sci. 1995, 120, 808-813. [CrossRef]

28. Pierik, R.; Djakovic-Petrovic, T.; Keuskamp, D.H.; de Wit, M.; Voesenek, L.A.C.J. Auxin and ethylene regulate elongation responses to neighbor proximity signals independent of gibberellin and DELLA proteins in Arabidopsis. Plant. J. 2009, 149, 1701-1712. [CrossRef]

29. Lin, C. Plant blue-light receptors. Trends Plant. Sci. 2000, 5, 337-342. [CrossRef]

30. Merzlyak, M.N.; Gitelson, A.A. Why and what for the leaves are yellow in autumn? On the interpretation of optical spectra of senescing leaves (Acer platanoides L.). J. Plant. Physiol. 1995, 145, 315-320. [CrossRef]

31. Kasperbauer, M.J.; Peaslee, D.E. Morphology and photosynthetic efficiency of tobacco leaves that received end-of-day red or far red light during development. Plant. Physiol. 1973, 52, 440-442. [CrossRef]

32. Roth-Bejerano, N.; Itai, C. Phytochrome involvement in stomatal movement in Pisum sativum, Vicia faba and Pelargonium sp. Physiol. Plant. 1987, 70, 85-89. [CrossRef]

33. Kasperbauer, M.J.; Hamilton, J.L. Chloroplast structure and starch grain accumulation in leaves that received different red and far-red levels during development. Plant. Physiol. 1984, 74, 967-970. [CrossRef] [PubMed]

34. Wherley, B.G.; Gardner, D.S.; Metzger, J.D. Tall fescue photomorphogenesis as influenced by changes in the spectral composition and light intensity. Crop. Sci. 2005, 45, 562-568. [CrossRef]

35. Sleeman, J.D.; Dudley, S.A.; Pannell, J.R.; Barrett, S.C.H. Responses of carbon acquisition traits to irradiance and light quality in Mercurialis annua (Euphorbiaceae): Evidence for weak integration of plastic responses. Am. J. Bot. 2002, 89, 1388-1400. [CrossRef]

36. Doroszewski, A. Spectral composition of radiation as the control factor for habit and yield of wheat. In Monographs and Scientific Dissertations; Institute of Soil Science and Plant Cultivation-State Research Institute: Puławy, Poland, 2011; Volume 28, p. 141. (In Polish)

37. Staniak, M. Response of selected species and cultivars of forage grasses to water shortage in the soil. In Monographs and Scientific Dissertations; Institute of Soil Science and Plant Cultivation-State Research Institute: Puławy, Poland, 2013; Volume 38, p. 217. (In Polish)

38. Czarnowski, M.; Starzecki, W. Inhibition of photosynthesis in tomato leaves by strong irradiation at increased $\mathrm{CO}_{2}$ concentrations. Acta Physiol. Plant. 1989, 11, 223-231.

39. Salisbury, C.D.; Chandler, J.M. Interaction of cotton (Gossypium hirsutum) and velvetleaf (Abutilon theophrasti) plants for water is affected by their interaction for light. Weed Sci. 1993, 41, 69-74. [CrossRef]

40. Hubac, C.; Guerrier, D.; Bousquet, U. Effect of far-red light on malate and potassium contents in cotton leaves: Relation to drought resistance. Physiol. Plant. 1986, 66, 37-40. [CrossRef]

41. Boccalandro, H.E.; Rugnone, M.L.; Moreno, J.E.; Ploschuk, E.L.; Serna, L.; Yanovsky, M.J.; Casal, J.J. Phyto-chrome B enhances photosynthesis at the expense of water-use efficiency in Arabidopsis. Plant. Physiol. 2009, 150, 1083-1092. [CrossRef]

42. González, C.V.; Ibarra, S.E.; Piccoli, P.M.; Botto, J.F.; Boccalandro, H.E. Phytochrome B increases drought tolerance by enhancing ABA sensitivity in Arabidopsis thaliana. Plant. Cell Environ. 2012, 35, 1958-1968. [CrossRef]

43. Sokolskaya, S.V.; Sveshnikova, N.V.; Kochetova, G.V.; Solovchenko, A.E.; Gostimski, S.A.; Bashtanova, O.B. Involvement of phytochrome in regulation of transpiration: Red-/far red-induced responses in the chlorophyll-deficient mutant of pea. Funct. Plant. Biol. 2003, 30, 1249-1259. [CrossRef]

44. Auge, G.A.; Rugnone, M.L.; Cortés, L.E.; González, C.V.; Zarlavsky, G.; Boccalandro, H.E.; Sánchez, R.A. Phytochrome A increases tolerance to high evaporative demand. Physiol. Plant. 2012, 146, 228-235. [CrossRef] [PubMed]

45. D'Amico-Damiāo, V.; Cruz, F.J.R.; Gavassi, M.A.; Santos, D.M.M.; Melo, H.C.; Carvalho, R.F. Photomorphogenic modulation of water stress in tomato (Solanum lycopersicum L.): The role of phytochromes A, B1, and B2. J. Horticult. Sci. Biotechnol. 2015, 90, 25-30. [CrossRef]

Publisher's Note: MDPI stays neutral with regard to jurisdictional claims in published maps and institutional affiliations. 